\title{
Describing soil surface microrelief by crossover length and fractal dimension
}

\author{
E. Vidal Vázquez ${ }^{1}$, J. G. V. Miranda ${ }^{2}$, and A. Paz González ${ }^{1}$ \\ ${ }^{1}$ Facultad de Ciencias, Universidade da Coruña, Spain \\ ${ }^{2}$ Instituto de Física, Universidade Federal da Bahia, Brazil
}

Received: 9 January 2007 - Revised: 26 March 2007 - Accepted: 27 March 2007 - Published: 30 May 2007

\begin{abstract}
Accurate description of soil surface topography is essential because different tillage tools produce different soil surface roughness conditions, which in turn affects many processes across the soil surface boundary. Advantages of fractal analysis in soil microrelief assessment have been recognised but the use of fractal indices in practice remains challenging. There is also little information on how soil surface roughness decays under natural rainfall conditions. The objectives of this work were to investigate the decay of initial surface roughness induced by natural rainfall under different soil tillage systems and to compare the performances of a classical statistical index and fractal microrelief indices. Field experiments were performed on an Oxisol at Campinas, São Paulo State (Brazil). Six tillage treatments, namely, disc harrow, disc plow, chisel plow, disc harrow + disc level, disc plow + disc level and chisel plow + disc level were tested. Measurements were made four times, firstly just after tillage and subsequently with increasing amounts of natural rainfall. Duplicated measurements were taken per treatment and date, yielding a total of 48 experimental surfaces. The sampling scheme was a square grid with $25 \times 25 \mathrm{~mm}$ point spacing and the plot size was $1350 \times 1350 \mathrm{~mm}$, so that each data set consisted of 3025 individual elevation points. Statistical and fractal indices were calculated both for oriented and random roughness conditions, i.e. after height reading have been corrected for slope and for slope and tillage tool marks. The main drawback of the standard statistical index random roughness, RR, lies in its no spatial nature. The fractal approach requires two indices, fractal dimension, $\mathrm{D}$, which describes how roughness changes with scale, and crossover length, $l$, specifying the variance of surface microrelief at a reference scale. Fractal parameters $\mathrm{D}$ and $l$, were estimated by two independent selfaffine models, semivariogram (SMV) and local root mean
\end{abstract}

Correspondence to: A. Paz González

(tucho@udc.es) square (RMS). Both algorithms, SMV and RMS, gave equivalent results for $\mathrm{D}$ and $l$ indices, irrespective of trend removal procedure, even if some bias was present which is in accordance with previous work. Treatments with two tillage operations had the greatest $\mathrm{D}$ values, irrespective of evolution stage under rainfall and trend removal procedure. Primary tillage had the greatest initial values of RR and $l$. Differences in $\mathrm{D}$ values between treatments with primary tillage and those with two successive tillage operations were significant for oriented but not for random conditions. The statistical index RR and the fractal indices $l$ and $\mathrm{D}$ decreased with increasing cumulative rainfall following different patterns. The $l$ and D decay from initial value was very sharp after the first $24.4 \mathrm{~mm}$ cumulative rainfall. For five out of six tillage treatments a significant relationship between $\mathrm{D}$ and $l$ was found for the random microrelief conditions allowing a covariance analysis. It was concluded that using RR or $l$ together with $\mathrm{D}$ best allow joint description of vertical and horizontal soil roughness variations.

\section{Introduction}

Fractal geometry is a useful tool for the analysis of the topography of different surfaces types and interfaces, including rocks (Power and Tullis, 1991), soils (Huang and Bradford, 1992; Davis and Hall, 1999; Vidal Vázquez et al., 2005, 2006), landscape (Pachepsky and Ritchie, 1998), earthatmosphere boundary layer (Keirsbulck et al., 2002) and industrial processed materials (Saitou et al., 2001; Klinger et al., 2006). In the context of agricultural soils, interest of assessing microtopography centres on the effect of surface roughness on storage of rain water, runoff generation and sediment production (Huang and Bradford, 1990; Hairsine et al., 1992; Kamphorst et al., 2000; Darboux et al., 2002; Darboux and Huang, 2005; Bertol et al., 2006). Accurate description of soil surface microerelief is also essential for

Published by Copernicus GmbH on behalf of the European Geosciences Union and the American Geophysical Union. 
modelling erosive processes (Jetten et al., 1999; FavisMortlock et al., 2000; Takken et al., 2001; Vidal Vázquez, 2002).

Agricultural practices induce an oriented roughness that is characteristic to a specific tillage tool (Allmaras et al., 1966; Huang, 1998). At the microplot scale, the spatial distribution of aggregates and clods is referred to as the random roughness (Allmaras et al., 1966). Common roughness assessment of soil surface microrelief usually follow a standardized procedures based on the random roughness index (RR), which is defined as the standard deviation among point elevation data after removing effects of oriented roughness (Allmaras et al., 1966; Currence and Lovely, 1970; Hansen et al., 1999). Geostatistical indices of roughness also have been proposed and tested for their ability to characterize soil surface microrelief (Linden and van Doren, 1986).

There are many ways in which the soil surface roughness may be changed with natural or imposed causes. Soil tillage may modify surface roughness by breaking large clods into smaller ones and by introducing mounds, rips and furrows. The amount of rainfall that reaches an uncovered soil surface may also be an important factor that can cause changes in its roughness. Usually microrelief features produced by tillage will smooth out as the rainfall amount increases which induces a decay of surface roughness as a function of cumulative rainfall.

In standard random roughness assessment it is assumed that microrelief vary continuously and smoothly from point to point. However, it is well known that many physical processes can operate on soil at different scales leading to structures which can appear to vary in a fractal manner (e.g. Armstrong, 1986; Miranda and Paz González, 2002; Vidal Vázquez et al., 2005) or more probably like short-range "multifractals" with a partition of fractal domains and dimensions for different parts of the system, as recently suggested (Burrough, 2001; Roisin, 2007). It is also reasonable to consider that patterns of soil microrelief production and decay are the result of processes acting together at different scales. Consequently, variations may be expected over several levels of scale and resolution.

Taken into account the monofractal approach, surface roughness can be described using self-similar and self-affine fractal models (Huang, 1998; Miranda, 2000). If a surface is self-similar, a small portion of the surface, when magnified isotropically, will appear statistically identical to the entire surface. Thus, the term "fractal" is often taken to be synonymous with "scale-invariance", the well-known property that many geologic and soil characteristics look the same at all scales. However, for topography and surface roughness, scale-invariance is rare. More commonly, the vertical and horizontal axes of a surface scale at different rates. This behavior is called self-affinity.

At least two parameters are required to describe roughness by a fractal model; one parameter typically describes how roughness changes with scale, while the other specifies the variance of surface microrelief at a reference scale. The two fractal parameters commonly used for soil surface roughness assessment are fractal dimension, $\mathrm{D}$, and crossover length, $l$. Fractal indices $\mathrm{D}$ and $l$ account for the multiscale effects and for the fluctuations of local vertical statistics, respectively (Huang and Bradford, 1992; Eltz and Norton, 1997; Huang, 1998; Miranda, 2000; Vidal Vázquez et al., 2005).

The scales involved in relief or microrelief analysis represent an important aspect to consider for understanding natural or imposed processes modifying surface roughness. Perception of soil surface topography depends on three main components of the sampling design:

1) The size of the sampling unit, which is the surface area of any particular measurement. Large sample units filter out spatial variation occurring at scales finer than their size. On the other hand, a small sampling unit is less representative of the sampling station. Most of the available soil topography data sets have been acquired at scales of about $1 \times 1 \mathrm{~m}^{2}$ or even smaller (Eltz and Norton, 1997; Merril et al., 2001; Vidal Vázquez et al., 2006).

2) The sampling interval defined as the distance between neighbouring point elevation measurements. Advances in surface roughness analysis have been driven by technologies used for data acquisition. Profile record by pinmeter is a relatively old but still rather common approach (Merril et al., 2001; Vidal Vázquez, 2002; Vidal Vázquez et al., 2006) with a grid resolution of the order of centimeters, whereas the resolution of non contact laser scanning, a technology available since the 1980s, provides data sets with millimeter resolution (Huang and Bradford, 1990; Huang, 1998).

3) The extent of the area being sampled, which determines the broadest spatial process that can be accounted for. For example spatial and temporal generation of overland flow depends on processes triggered at large plot or catchments level, whereas spatial correlation of soil structural units such as aggregates or clods may be assessed at the small plot scale (Darboux et al., 2002). Notice that increase in scaling may be achieved using equipment with higher resolution or devices providing point elevation data over larger areas (Merril et al., 2001).

Although several investigations have reported fractal analysis of soil surface roughness in sampling units of variable size at the milimetric (e.g. Huang and Bradford, 1992; Eltz and Norton, 1997) and centimetric (e.g. Miranda 2000; Vidal Vázquez et al., 2005, 2006) grid resolutions, assessment of fractal roughness indices is more the exception than the rule. Consequently the statistical standard roughness estimation procedure is the most frequently used (Hansen et al., 1999; Kamphorst et al., 2000). Advantages of fractal analysis in soil microrelief assessment have been recognised but the use of fractal indices in practice remains challenging. The difficulties may lie in the relatively small sensitivity of the fractal dimension index, D, to characterize differences in soil tillage treatments when compared with other indices, for example RR or $l$. Moreover, most of the microrelief data series 
Table 1. Summary of tillage treatments and cumulative rainfall $(\mathrm{mm})$ corresponding to field measurements of surface roughness.

\begin{tabular}{llllll}
\hline $\begin{array}{l}\text { Tillage treatment } \\
\text { Disc plow }\end{array}$ & Disc harrow & Chisel plow & $\begin{array}{l}\text { Disc plow } \\
+ \text { levelling }\end{array}$ & $\begin{array}{l}\text { Disc harrow } \\
+ \text { levelling }\end{array}$ & $\begin{array}{l}\text { Chisel plow } \\
+ \text { levelling }\end{array}$ \\
\hline 0 & 0 & 0 & 0 & 0 & 0 \\
24.4 & 24.4 & 24.4 & 24.4 & 24.4 & 24.4 \\
113.8 & 120.9 & 120.9 & 232.8 & 232.8 & 232.8 \\
232.8 & 232.8 & 232.8 & 294.6 & 294.6 & 294.6 \\
\hline
\end{tabular}

analyzed by fractal techniques have been acquired by highresolution devices, like laser scanner, at the 1 to $2 \mathrm{~mm}$ scale. This notwithstanding, in a previous work (Vidal Vázquez et al., 2006) it was also shown that the fractal approach was useful for characterizing soil random roughness of initial tilled surfaces as depicted by low technology devices such as pinmeter.

Soil surface roughness decay under natural rainfall conditions has been studied little. The main purpose of this work were to investigate the decay of initial surface roughness induced by natural rainfall under different soil tillage systems and to analyze the relevancy of the fractal approach for data sets acquired by pinmeter on a cultivated Oxisol.

\section{Material and methods}

\subsection{Soil, site and tillage operations}

Field data for the present study were obtained at the experimental station of Agronomical Institute of Campinas (IAC), in São Paulo, Brazil. The experimental site is located at $22^{\circ} 53^{\prime} \mathrm{S}$ and $47^{\circ} 04^{\prime} \mathrm{W}$, at an average altitude of $600 \mathrm{~m}$ above sea level. The mean annual rainfall at the study site is approximately $1380 \mathrm{~mm}$, from which about 1050 correspond to the rainy season lasting from October to March during austral summer.

The soil was classified as an Oxisol (Soil Survey Staff, 1993), equivalent to a "Latossolo Vermelho Eutroférrico tipico" (EMBRAPA, Brazilian Soil Classification System, 1999). The topsoil (0-20 cm depth) was clay textured (41\% sand, $8 \%$ silt and $51 \%$ clay), organic carbon content was 3.79 $\%$ and it had an slowly acid $\mathrm{pH}\left(\mathrm{pH}_{\mathrm{H} 20}=5.9\right.$ and $\left.\mathrm{pH}_{\mathrm{KCl}}=5.5\right)$.

Field microrelief measurements were made by means of a pinmeter between October and November 2000, at an experimental site with $5.10 \%$ slope. A total of 48 data sets were obtained corresponding to six tillage treatments, two replications per treatment and four successive dates. The initial measurement was performed just after tillage, i.e. before any rain, and the other three were taken subsequently with increasing cumulative amounts of natural rainfall. The three primary tillage treatments studied were disc plow, disc harrow and chisel plow, with cumulative natural rains of $0,24.4$,
113.3 (for disc plow), 120.9 (for disc harrow and chisel plow) and $232.8 \mathrm{~mm}$. Besides these, the following treatments with two tillage operations were also assessed: disc plow plus leveling disc, disc harrow plus leveling disc, chisel plow plus leveling disc with cumulative natural rains of $0,24.4,232.8$ and $294.6 \mathrm{~mm}$. Table 1 summarizes tillage treatments and cumulative rainfall for all measured surfaces. Note that cumulative rain by the third and fourth sampling dates varied between tillage treatments. This was because of the small length of the dry period intervals between two consecutive rain events following typical rain patterns of the austral summer in São Paulo State, Brazil.

\subsection{Field data sets}

Each of the 48 data sets consisted of point elevation measurements recorded by pinmeter (Wagner and Yiming Yu, 1991) with horizontal and vertical resolutions of $25 \mathrm{~mm}$ and $0.01 \mathrm{~mm}$ respectively and a vertical range of approximately $400 \mathrm{~mm}$. The sampling scheme was a square grid of $25 \times 25 \mathrm{~mm}$ and the total plot area was $1350 \times 1350 \mathrm{~mm}$. Thus each $1350 \mathrm{~mm}$ experimental profile consisted of 55 point elevation data and 55 profiles per plot were taken, yielding a total of 3025 data points per measurement.

Manual pinmeters are destructive devices. Thus different plots were used for microtopography measurements at increasing amounts of cumulative rainfall in successive dates. Within each tillage treatment, experimental plots were located as close as possible to minimize the effect of spatial variability between them. However, this procedure introduces some bias in assessing temporal decay of soil surface roughness per treatment. In other words, a microrelief sampled in a given plot at a given date does not follow faithfully the characteristics of a microrelief that has been sampled on a different plot at a different date. Thus, even though two sets of measurements were taken for each combination of tillage treatment and cumulative rainfall, they are not considered in this analysis as replications, but rather, as two independent measurements for each situation.

Trends due to plot slope and slope + agricultural practices, were removed by a standard procedure (Currence and Lovely, 1970). Between the methods described by these 


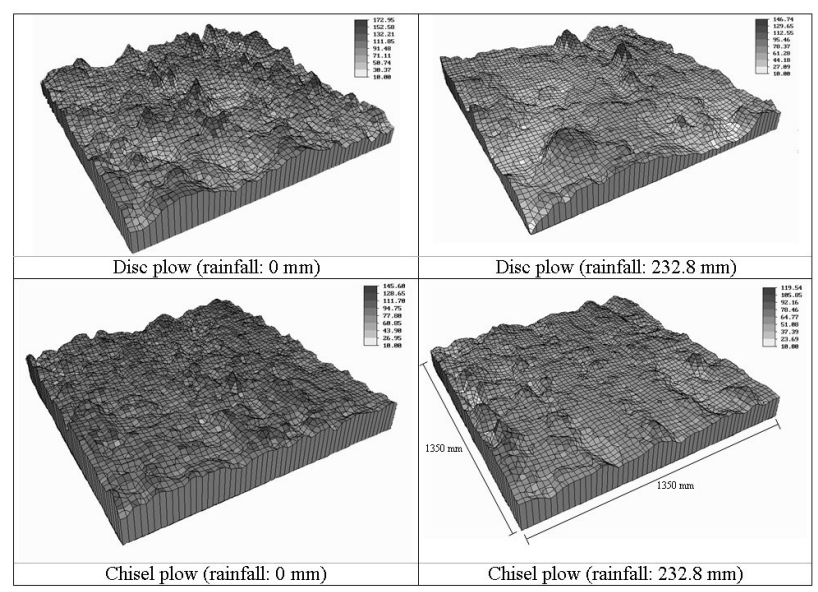

Fig. 1. Examples of random microrelief for different tillage conditions and cumulative rainfall amounts.

authors the fourth and the fifth were used, which allows distinguishing between oriented and random roughness, respectively. The oriented roughness condition results from correction for slope using the plane of best fit for each plot and it is thought to include periodic effects due to tillage. Random roughness condition is considered to be associated to disordered microrelief initiated by the random disposition of aggregates and clods on the soil surface and was obtained after removing of row and column trend effects (Huang, 1998; Vidal Vázquez, 2002; Vidal Vázquez et al., 2005). The configuration of soil topography was single described by a set of points of known $\mathrm{x}-, \mathrm{y}-$ and $\mathrm{z}$-coordinates. The elevation values given as a function of the horizontal coordinate system provide a numerical representation of the surface and constitute a digital elevation model (DEM). From each experimental data set of topography two DEMs were obtained, representing the oriented and the random roughness condition. Examples of DEM for the study treatments, conventional and direct drilling, are shown in Figs. 1 and 2, respectively. These plots were drawn with an identical scale factor to provide a realistic view of the soil surface microrelief and of its changes with time.

\subsection{Statistical and fractal roughness indices}

In this study three different roughness indicators have been assessed, a classical index, RR (Random Roughness) describing vertical statistics, and two fractal indices, fractal dimension, $\mathrm{D}$, and crossover length, $l$. Random roughness is estimated simply as the standard deviation of the individual point data. Calculations were performed in both, oriented and random data sets after correction of the original point elevation measurements as before described.

From a review of methods proposed to estimate fractal indices $\mathrm{D}$ and $l$ from soil topography surfaces or transects,
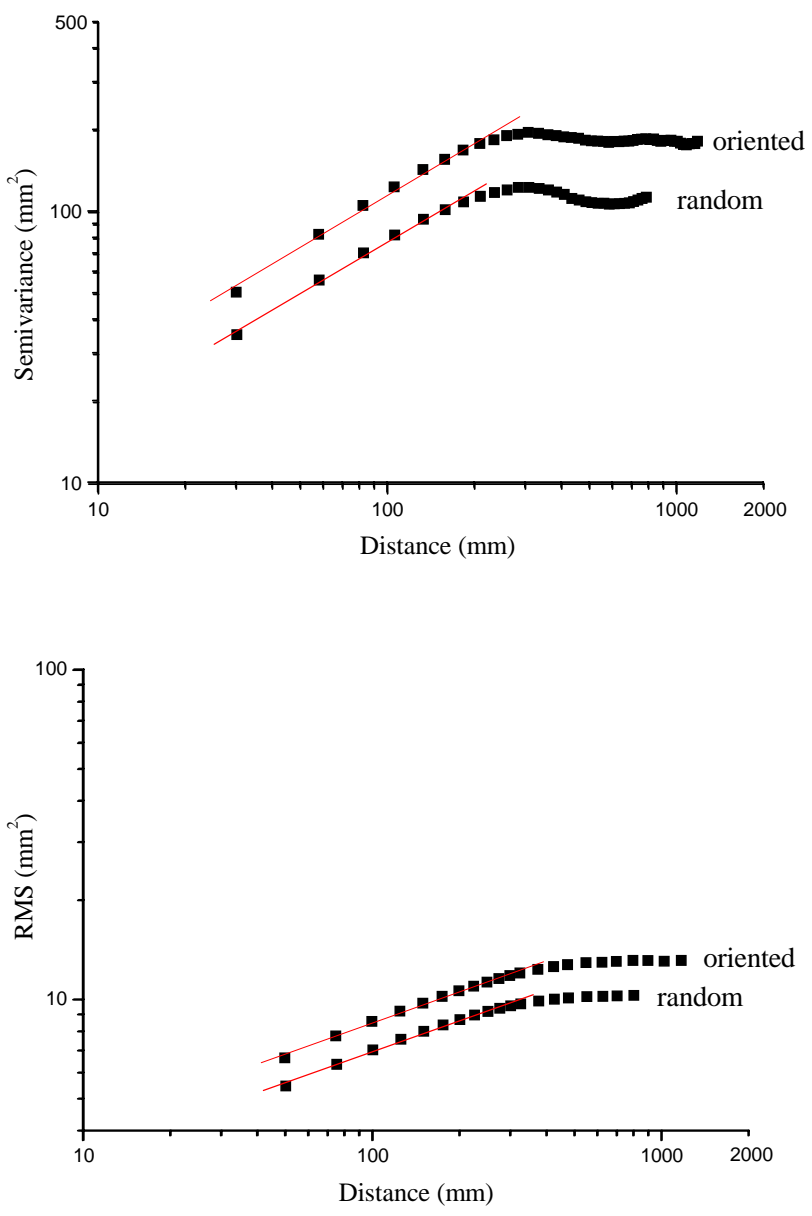

Fig. 2. Roughness semivariance (SMV) and root-mean-square (RMS) functions versus scale, before and after tillage marks trend removal. Before trend removal: $\mathrm{D}_{\mathrm{SMV}}=2.68, \mathrm{D}_{\mathrm{RMS}}=2.69$; after trend removal: $\mathrm{D}_{\mathrm{SMV}}=2.69, \mathrm{D}_{\mathrm{RMS}}=2.69$.

(Miranda, 2000; Miranda and Paz González, 2002; Vidal Vázquez, 2002; Vidal Vázquez et al., 2005), it follows that results may show a wide variability depending on the assumptions made in formulating the fractal model used and the resulting algorithm. Taking into account that roughness is better described by a self-affine or by prefactal models, typically $\mathrm{D}$ and $l$ estimates may be obtained from two algorithms, i.e. semivariance and root-mean-square. Both methods are based on the calculation of the Hurst exponent, $\mathrm{H}$, from which the fractal dimension and crossover length are assessed.

The use of semivariogram for estimating fractal dimension of soil transects was first introduced by Armstrong (1986) and later on applied to various surface types (Carr and Benzer, 1991; Bolviken et al., 1992) including agricultural soils (Huang and Bradford, 1992).

The first step in the estimation of the fractal dimension, $D_{\mathrm{SMV}}$, is the calculation of the experimental semivariogram, 
which is defined as:

$$
\gamma^{*}(h)=\frac{1}{2 N(h)} \sum_{N(h)}^{i=1}\left[Z\left(x_{i}+h\right)-Z\left(x_{i}\right)\right]^{2}
$$

Where $\gamma(h)$ is the semivariance, $h$ is the lag distance between points, $Z(x)$ is the elevation at location $x$ and $N(h)$ is the number of pairs considered. Equation (1) gives a relationship between a variance term $\gamma(h)$ based on elevation difference and the separation length, $h$.

For a fractal transect the variogram, according to Mandelbrot (1983, p 353) follows the equation:

$\gamma(h)=K h^{2 H}$

Where the exponent of the incremental function, $\mathrm{H}$, is the Hurst exponent. The power model that describes a selfsimilar fractal corresponds to a phenomenon with an unlimited capacity for spatial dispersion and with an undefined a priori variance.

Assuming a fractal Brownian motion ( $\mathrm{fBm}$ ) model, the Hurst exponent, $H$, is allowed to vary from 0 to 1 (Huang and Bradford, 1992). In this case, the $\log -\log$ behavior of the semivariogram may be described as a function of the crossover length, $l$, and the Hurst exponent, $\mathrm{H}$, as:

$\gamma(h)=l^{1-H} h^{H}$

Thus, the fractal dimension of a fractal surface or profile represented by its semivariogram can be estimated by examining the slope of the semivariance, $\gamma(h)$, versus the lag distance, $h$, when plotted on a double logarithmic scale. Once the Hurst exponent, $H$, is obtained by Eq. (3), the fractal dimension, $D_{\mathrm{SMV}}$, of a soil surface is computed from these and the Euclidean dimension $(d=3)$ as:

$D_{\mathrm{SMV}}=3-H$

Finally, as described by Huang and Bradford (1992), the crossover length, $l$, may be estimated by:

$l_{\mathrm{SMV}}=\exp [(a / 2-2 H)]$

Where, $a$, is the intercept of the straight line of the RMS plot at the y-axis.

Fractal indices D and $l$ were also calculated from the average deviation around the mean elevation value (RMS) of all points located inside a square window with size $h$. Rootmean-square may be estimated in different ways, both for profiles and surfaces (Malinverno, 1990; Gallant et al., 1994; Moreira and Da Silva, 1994). Average values of RMS, denoted as $\bar{W}(h)$ for different scale ranges $\mathrm{h}$, were computed according to the algorithm:

$\bar{W}(h)=\frac{1}{N_{h}} \sum_{u=1}^{N_{h}}\left\{\frac{1}{m_{h}} \sum_{i \in h}\left[Z\left(x_{i}, y_{i}\right)-\bar{Z}_{h}\right]^{2}\right\}^{1 / 2}$

Where, $\mathrm{N}_{h}$ is the total number of windows of size $h, \mathrm{~m}_{h}$ is the number of points in a window of size $h, \mathrm{Z}\left(\mathrm{x}_{i}, \mathrm{y}_{i}\right)$ are data point elevations regularly spaced over surface and $\bar{Z} h$ represents the average elevation value for all points in the $\mathrm{i}^{\text {th }}$ window.

Windows of the same size are situated all over the surface, the RMS for each one is calculated and then the average value of all obtained. This procedure is then repeated with windows of different sizes. Assuming fractal behavior, the slope of the log-log plot of the structural function, $\bar{W}(h)$, versus the scale, $h$, gives an estimation of the Hurst exponent, $\mathrm{H}$.

When using a fractal Brownian motion model, the straightline portion of the function $\bar{W}(h)$ versus distance $h$, near the origin may be described by the crossover length and the fractal dimension as:

$\bar{W}(h)=l^{1-H} h^{H}$

Again, the fractal dimension, $\mathrm{D}_{\mathrm{RMS}}$, of the soil surface is obtained from the Hurst exponent and the Euclidean dimension $\mathrm{d}=3$ according to the corresponding equation similar to Eq. (4), whereas crossover length, $l_{\mathrm{RMS}}$, is derived from the structural function, $\bar{W}(h)$ with an expression similar to Eq. (5).

\section{Results and discussion}

\subsection{Parameter estimation}

Examples of the structural functions semivariance, $\gamma(h)$, and root-mean-square, $\bar{W}(h)$,for roughness plotted on a double logarithm scale are graphed in Fig. 2. Both curves show a straight-line portion of the variogram and the root-meansquare functions with a steep slope at short lag distances and then a second portion with a gentle slope for the longest lag distances. The first straight line portion of the structural functions $\gamma(h)$ and $\bar{W}(h)$ is quantified by the self-affine model.

For both the oriented and the random roughness conditions of all the studied surfaces, the first portion of the structural functions $\gamma(h)$ and $\bar{W}(h)$ in a log-log diagram, showed a similar trend indicating the existence of a correlation. For large lag distances, after break in scale, the relationship between the log of the structural functions $\gamma(h)$ and $\bar{W}(h)$, and the $\log$ of distance becomes typically non-linear for surfaces with oriented roughness, whereas for the random roughness condition shows a tendency to be linear; a weak correlation between structural function and distance may persist or may be absent. Thus, stable estimates of fractal indices were obtained only from the first segment of the structural functions $\gamma(h)$ and, $\bar{W}(h)$ before the scale break in slope. A fractal roughness which spectrum will be limited at low frequencies is an expected result, since the break in scale is mainly related to the size of the structural units at the soil surface and is in accordance with previous works on soil surfaces recorded by pinmeter (Miranda, 2000; Vidal Vázquez et al., 2005, 2006) and by laser scanning (Huang and Bradford, 1992; Eltz and 
Norton, 1997; Davis and Hall, 1999; Vidal Vázquez et al., 2005).

The lower limits of the range of fractal self-affinity were quite constant for each of the two algorithms used in computing fractal indices, so that they were estimated at 30 and $50 \mathrm{~mm}$ when estimated by semivariogram and root-meansquare functions respectively. Notice also that the concept of fractal dimension is only properly defined when using an asymptotic limit to infinitely small length. As expected, the lower cutoff of the fractal regime described by the $\gamma(h)$ structural function, i.e. $30 \mathrm{~mm}$ is of the same order of magnitude than the grid horizontal resolution, i.e. $25 \mathrm{~mm}$. Differences between the lower cutoff estimated by SMV and RMS methods are explained by the fact that the first lag of the semivariogram was calculated for a distance equivalent to a grid spacing, whereas the first point of the root-mean-square function was computed for a larger initial window size. In contrast the upper limit of the fractal regime showed a wider range of variation. For surfaces with oriented roughness the upper cutoff was between 82 and $360 \mathrm{~mm}$ when estimated from the semivariogram and between 150 to $900 \mathrm{~mm}$ when using the root-mean-square function. The fact that the scale break consistently is somewhat further away on calculations are performed by the RMS algorithm is an expected result. The order of magnitude at which scales breaks, when using the SMV function approximately matches the characteristics size of the larger clods on the soil surface. The scale at which the fractal dimensions change has been considered a parameter of considerable interest and has been referred to as the correlation length (Vidal Vázquez, 2002; Miranda and Paz González, 2002; Vidal Vázquez et al., 2006).

In each of the studied surfaces, the ratio between the upper $\left(l_{2}\right)$ and the lower $\left(l_{1}\right)$ cutoff $\left(l_{2} / l_{1}\right)$ of the structural functions $\bar{W}(h)$ and $\gamma(h)$ largely exceeds $2^{1 / D}$, which is the minimal condition to accept an experimental $\mathrm{D}$ value over a range of fractal self-affinity.

Table 2 lists mean values and errors of fractal dimension; $\mathrm{D}_{\mathrm{RMS}}$, and crossover length, $l_{\mathrm{RMS}}$, estimated by the root mean square algorithm for each of the 48 random surfaces, together with mean values of the RR index used as a reference. The coefficients of correlation for the straight-line portion of the structural function $\bar{W}(h)$ were between 0.990 and 0.999. The number of couples of data of the structural function, $\bar{W}(h)$ versus the scale used in the linear regression varied between 6 and 20. The errors in estimating $D_{R M S}$ varied between 0.0018 and 0.0112 , whereas absolute errors in estimating $l_{\mathrm{RMS}}$ ranged from 0.023 to 0.608 . When taking into account relative values the magnitude of errors in estimating $l_{\text {RMS }}$ for the surfaces with random microrelief results lower than $10 \%$ of the absolute value. Relative errors of $D_{\text {RMS }}$ estimates were much lower.

When using the semivariogram algorithm, the coefficients of correlation for the straight-line portion of the $\gamma(h)$ structural function were between 0.991 and 1.000 for the random roughness condition of the 48 surfaces. Linear regressions between $\gamma(h)$ and scale were calculated with couples of data ranging from 4 to 14 . $\mathrm{D}_{\text {SMV }}$ was estimated with larger errors than $\mathrm{D}_{\mathrm{RMS}}$ in the range from 0.004 to 0.044 , whereas errors in estimating $l_{\mathrm{SMV}}$ ranged from 0.039 to 0.111 , also larger than the corresponding $l_{\text {RMS }}$ errors (data not shown).

Likewise, the straight line portion at short lag distances of the $\bar{W}(h)$ and $\gamma(\mathrm{h})$ structural functions of the surfaces with oriented roughness induced by agricultural practices were fitted by linear regression with scale, being the coefficients of correlation in the range from 0.998 to 0.999 and from 0.986 to 0.999 respectively. For this type of surfaces, also errors in estimating $l_{\mathrm{RMS}} l_{\mathrm{SMV}}$, were lower than those corresponding to $D_{\text {RMS }}$ and $D_{\text {SMV }}$. The estimates of fractal dimension and crossover length obtained by the semivariogram and rootmean-square algorithms are graphed in Fig. 3. In this graph both surfaces with conditions of oriented and random roughness are compared, yielding a total of 84 couples of data for $\mathrm{D}$ and $l$ fractal indices.

Coefficient of correlation between fractal dimension values estimated by RMS and SMV algorithms was as high as $\mathrm{r}^{2}=0.933$. This notwithstanding, there is some bias between results obtained by both estimation methods, so that when $\mathrm{D}$ approaches 2.5 or it is lower, values obtained with the RMS method are higher than those resulting from SMV algorithm, whereas when D approaches 2.9 the opposite is true and SMV values show a tendency to be higher.

Fractal dimension estimated by the semivariogram method, $\mathrm{D}_{\mathrm{SMV}}$, after corrections for slope (oriented roughness), was between 2.326 and 2.889 and after correction for slope and agricultural marks (random roughness) was between 2.618 and 2.919. When estimations were made with the root-mean-square method $\mathrm{D}_{\mathrm{RMS}}$ values ranged from 2.429 and 2.843 for oriented roughness and from 2.650 and 2.869 for random roughness condition. Thus, when agricultural marks are removed (random roughness) values of fractal dimension increase, irrespective of tillage treatment and calculation method. Moreover, for the oriented roughness condition $\mathrm{D}$ values may be persistent $(\mathrm{D}<2.5)$ or antipersistent $(\mathrm{D}>2.5)$, whereas all $\mathrm{D}$ values for random surfaces clearly are antipersistent $(\mathrm{D}>2.5)$. Higher values of $\mathrm{D}$ indicate a more rugged surface, with variation occurring mostly at finest scale.

Crossover length values estimation by the semivariogram and the root-mean-square method, $l_{\mathrm{SMV}}$ and $l_{\mathrm{RMS}}$, respectively produced also close results, being the correlation coefficient $r^{2}=0.976$. However, some bias was also apparent (Fig. 3) in that the crossover length values estimated by the root-mean-square method $l_{\mathrm{RMS}}$ were lower than those estimated from the semivariogram structural function, $l_{\mathrm{SMV}}$.

Like RR, the crossover length, $l_{\mathrm{RMS}}$ or $l_{\mathrm{SMV}}$ also characterizes vertical variations of soil roughness. For the random roughness condition, the mean crossover length estimated by the root-mean-square algorithm was $3.574 \mathrm{~mm}$ and the minimum and maximum were 1.160 and $12.156 \mathrm{~mm}$, respectively. When using the semivariogram function for 

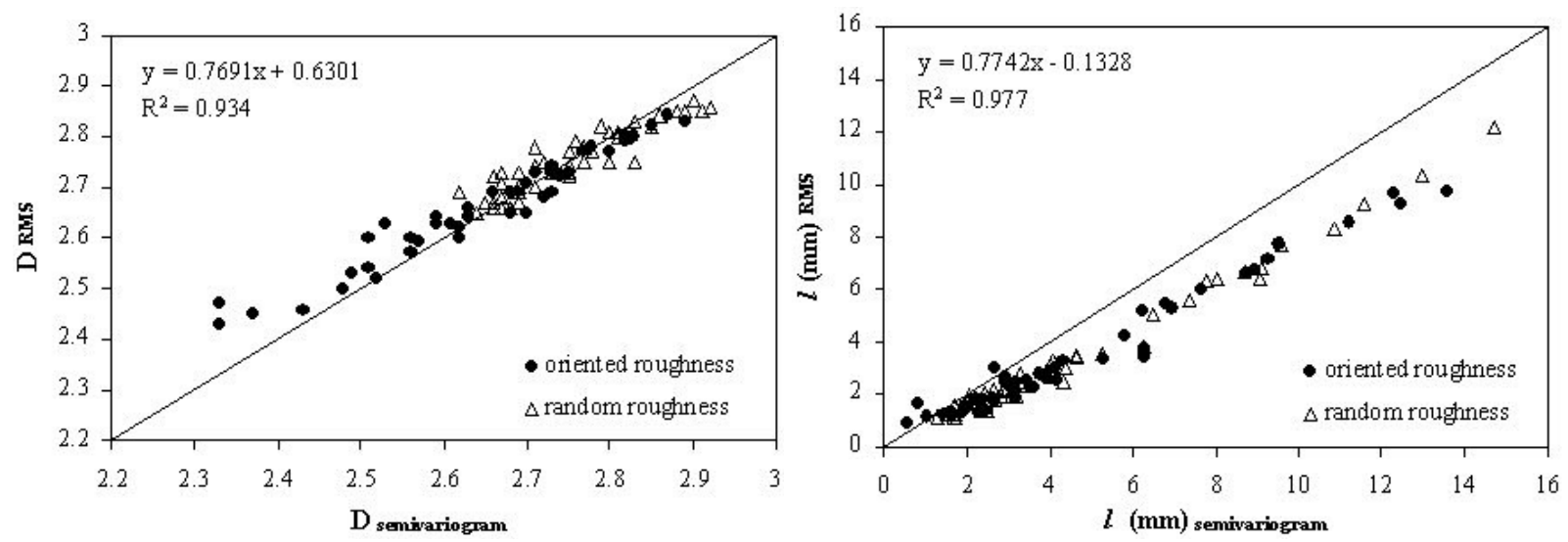

Fig. 3. Comparison of fractal dimension, D, and crossover length, l, values estimated by semivariogram (SMV) and root-mean-square (RMS) algorithms.

this roughness condition $l_{\mathrm{SMV}}$ values were: mean $4.763 \mathrm{~mm}$, minimum $1.266 \mathrm{~mm}$ and maximum $14.694 \mathrm{~mm}$.

The above results clearly indicate a larger variation in scale of the crossover length, $l$, when compared with the fractal dimension, D. This reinforces the relevancy of the crossover length parameter, $l$, as a discriminator of vertical differences in roughness. In surface roughness quantification the fractal dimension, $\mathrm{D}$, can be taken as a relative measure of the distribution of different sized structural elements on the soil surface (Huang, 1998). In this context, it should be stressed, that fractal dimension is a descriptor of horizontal variations of soil roughness, which implies that it has to be considered in connection with an index describing differences in roughness height (Huang 1998; Vidal Vázquez et al., 2006).

All the studied microrelief data sets exhibited self-affine properties at a limited range of scales. Consequently, description of soil surface roughness as a stationary random variable is inadequate at least at the microplot scale. Stable estimates of the two fractal indices, fractal dimension, D, and crossover length, $l$, were obtained by two different algorithms, semivariogram and root-mean-square. Thus, the use of fractal indices should improve the characterization of soil surface microrelief obtained from a single parameter, such as the classical RR indicator.

In our work, spatial correlation at scales smaller than a few centimeters was found on both, oriented and random structural features. This is in accordance with several previous studies showing that random roughness was correlated at short distances (millimeters to decimeters) and that above this distance correlation tends to disappear (Linden and van Doren, 1986; Huang and Bradford, 1992; Huang 1998, Miranda, 2000; Miranda and Paz González, 2002; Darboux and Huang, 2005). The relationship between aggregates and/or clods size and range of spatial correlation was well illustrated by Vidal Vázquez et al. (2005). This work showed milimetric spatial correlation for artificial surfaces constituted by small aggregates prepared under laboratory conditions and centimetric spatial correlation for field surfaces with large clods resulting from different tillage practices.

\subsection{Rainfall and tillage effects on fractal indices}

Mean values for the statistical index RR as well as the fractal indices $\mathrm{D}$ and $l$ for treatments with primary tillage versus treatments with two successive tillage operations are shown in Fig. 4. Graphed values are those estimated by RMS algorithm, $\mathrm{D}_{\mathrm{RMS}}$ and $l_{\mathrm{RMS}}$, after correction for agricultural marks, i.e. random surface conditions. Table 2 lists RR, D and $l$ estimations for each of the 48 studied surfaces with random features. Treatments with primary tillage exhibited higher values of the vertical roughness component, according with RR and $l_{\mathrm{RMS}}$ indices at the initial state $(0 \mathrm{~mm}$ rain). This is an expected result, since the second tillage operation with a levelling disc reduces microrelief height. Prior to any rain, the rank of RR and $l_{\mathrm{RMS}}$ values both in the primary tillage as well as in treatments with two tillage operations was as follow: disk plow $>$ disk harrow $>$ chisel plow, had the greatest. Between treatments of these two groups of surfaces there were some overlaps regarding RR and $l_{\mathrm{RMS}}$ values.

Overall, RR and $l_{\text {RMS }}$ decreased with increasing rainfall, in such a way that difference between treatments with primary tillage and with two successive operations continued to be apparent along the successive stages of roughness decay by cumulative rainfall.

Both RR and $l_{\text {RMS }}$ exhibited a clear trend to decrease when graphed versus rainfall amount, but RR values changed more slowly than $l_{\text {RMS }}$ values. Mean values of the fractal indices, $l_{\text {RMS }}$ and $D_{\text {RMS }}$ exhibit a rapid decrease from the reference initial state, to the subsequent state assessed after $24.4 \mathrm{~mm}$ cumulative rainfall. Thus the first rainfall event induced large microtopography roughness decay. Thereafter, increased 
Table 2. Calculated values of statistical (RR) and fractal indices (D an $l$ ) for surfaces with random roughness using the RMS algorithm as a function of cumulative rainfall and tillage treatment.

\begin{tabular}{|c|c|c|c|c|c|c|c|}
\hline Plot & Cumulative rainfall (mm) & $\begin{array}{l}\text { RR } \\
(\mathrm{mm})\end{array}$ & $\mathrm{D}$ & Standard error & $\begin{array}{l}l \\
(\mathrm{~mm})\end{array}$ & Standard error & $\mathrm{r}$ \\
\hline \multicolumn{8}{|c|}{ Disc harrow } \\
\hline 1 & 0 & 15.38 & 2.807 & 0.010 & 7.69 & 0.61 & 0.994 \\
\hline 2 & 0 & 17.21 & 2.797 & 0.006 & 8.32 & 0.45 & 0.996 \\
\hline 3 & 24.4 & 14.88 & 2.709 & 0.007 & 3.42 & 0.21 & 0.997 \\
\hline 4 & 24.4 & 17.62 & 2.727 & 0.008 & 3.24 & 0.23 & 0.996 \\
\hline 5 & 113.3 & 10.62 & 2.690 & 0.008 & 2.09 & 0.14 & 0.997 \\
\hline 6 & 113.3 & 12.65 & 2.665 & 0.002 & 1.40 & 0.02 & 1.000 \\
\hline 7 & 232.8 & 11.99 & 2.700 & 0.010 & 2.86 & 0.23 & 0.997 \\
\hline 8 & 232.8 & 9.01 & 2.748 & 0.009 & 2.33 & 0.16 & 0.996 \\
\hline \multicolumn{8}{|c|}{ Disc plow } \\
\hline 9 & 0 & 21.09 & 2.796 & 0.005 & 10.32 & 0.45 & 0.997 \\
\hline 10 & 0 & 23.41 & 2.827 & 0.006 & 12.16 & 0.67 & 0.994 \\
\hline 11 & 24.4 & 20.74 & 2.656 & 0.008 & 3.81 & 0.32 & 0.996 \\
\hline 12 & 24.4 & 18.58 & 2.676 & 0.008 & 3.61 & 0.28 & 0.996 \\
\hline 13 & 120.9 & 16.99 & 2.667 & 0.009 & 3.01 & 0.24 & 0.996 \\
\hline 14 & 120.9 & 14.24 & 2.663 & 0.010 & 2.87 & 0.26 & 0.997 \\
\hline 15 & 232.8 & 14.69 & 2.664 & 0.007 & 1.97 & 0.11 & 0.998 \\
\hline 16 & 232.8 & 14.24 & 2.650 & 0.006 & 1.98 & 0.11 & 0.998 \\
\hline \multicolumn{8}{|c|}{ Chisel plow } \\
\hline 17 & 0 & 11.83 & 2.848 & 0.008 & 6.43 & 0.41 & 0.993 \\
\hline 18 & 0 & 11.29 & 2.863 & 0.009 & 6.80 & 0.43 & 0.992 \\
\hline 19 & 24.4 & 8.62 & 2.725 & 0.013 & 1.96 & 0.19 & 0.994 \\
\hline 20 & 24.4 & 9.47 & 2.727 & 0.006 & 2.06 & 0.09 & 0.998 \\
\hline 21 & 120.9 & 8.97 & 2.768 & 0.004 & 2.35 & 0.08 & 0.998 \\
\hline 22 & 120.9 & 8.41 & 2.751 & 0.004 & 2.41 & 0.08 & 0.999 \\
\hline 23 & 232.8 & 10.35 & 2.671 & 0.008 & 1.71 & 0.12 & 0.997 \\
\hline 24 & 232.8 & 8.60 & 2.821 & 0.011 & 3.20 & 0.26 & 0.988 \\
\hline \multicolumn{8}{|c|}{ Disc harrow + disc level } \\
\hline 25 & 0 & 12.42 & 2.846 & 0.008 & 6.69 & 0.40 & 0.994 \\
\hline 26 & 0 & 10.74 & 2.853 & 0.009 & 5.64 & 0.39 & 0.990 \\
\hline 27 & 24.4 & 9.72 & 2.750 & 0.010 & 2.20 & 0.16 & 0.994 \\
\hline 28 & 24.4 & 11.58 & 2.729 & 0.005 & 2.16 & 0.08 & 0.998 \\
\hline 29 & 232.8 & 8.02 & 2.719 & 0.010 & 1.75 & 0.12 & 0.997 \\
\hline 30 & 232.8 & 8.96 & 2.726 & 0.003 & 1.93 & 0.05 & 0.999 \\
\hline 31 & 294.6 & 6.58 & 2.703 & 0.006 & 1.19 & 0.05 & 0.999 \\
\hline 32 & 294.6 & 9.91 & 2.736 & 0.006 & 1.68 & 0.08 & 0.997 \\
\hline \multicolumn{8}{|c|}{ Disc plow + disc level } \\
\hline 33 & 0 & 15.60 & 2.869 & 0.009 & 9.25 & 0.65 & 0.989 \\
\hline 34 & 0 & 14.51 & 2.812 & 0.006 & 6.40 & 0.33 & 0.995 \\
\hline 35 & 24.4 & 10.48 & 2.735 & 0.011 & 2.71 & 0.23 & 0.995 \\
\hline 36 & 24.4 & 10.59 & 2.781 & 0.012 & 3.47 & 0.32 & 0.991 \\
\hline 37 & 232.8 & 7.32 & 2.738 & 0.003 & 1.49 & 0.03 & 0.999 \\
\hline 38 & 232.8 & 7.65 & 2.770 & 0.012 & 1.82 & 0.15 & 0.993 \\
\hline 39 & 294.6 & 7.28 & 2.730 & 0.003 & 1.17 & 0.03 & 0.999 \\
\hline 40 & 294.6 & 11.38 & 2.686 & 0.005 & 1.52 & 0.07 & 0.998 \\
\hline \multicolumn{8}{|c|}{ Chisel plow + disc level } \\
\hline 41 & 0 & 10.36 & 2.840 & 0.010 & 5.01 & 0.38 & 0.990 \\
\hline 42 & 0 & 14.51 & 2.807 & 0.006 & 6.31 & 0.32 & 0.996 \\
\hline 43 & 24.4 & 10.79 & 2.742 & 0.010 & 2.41 & 0.18 & 0.995 \\
\hline 44 & 24.4 & 10.56 & 2.778 & 0.014 & 2.77 & 0.29 & 0.990 \\
\hline 45 & 232.8 & 6.97 & 2.803 & 0.004 & 2.21 & 0.07 & 0.997 \\
\hline 46 & 232.8 & 6.03 & 2.754 & 0.005 & 1.41 & 0.05 & 0.998 \\
\hline 47 & 294.6 & 3.76 & 2.818 & 0.003 & 1.16 & 0.03 & 0.998 \\
\hline 48 & 294.6 & 8.83 & 2.788 & 0.003 & 1.21 & 0.02 & 0.999 \\
\hline
\end{tabular}

amounts of natural rain showed a tendency to further decrease mean RR and $l_{\text {RMS }}$ values, but to a much lesser extent as during the first rainfall event. In the primary tillage treatments RR decayed by $90 \%$ from its initial values with the first $24.4 \mathrm{~mm}$ rainfall and by $69 \%$ with $232.8 \mathrm{~mm}$ cumulative rainfall. In contrast, $l_{\text {RMS }}$ decayed by 37 and $30 \%$ of its original value with 24.4 and $232.8 \mathrm{~mm}$ respectively.
Treatments with two tillage operations showed a similar tend of roughness decay characterised by a rapid decrease of initial roughness with the first rainfall event followed by a more slowly phase. Changes of initial reference roughness induced by rainfall were smaller in treatments with an additional levelling operation than in primary tillage treatments. cumulative rain increased. 


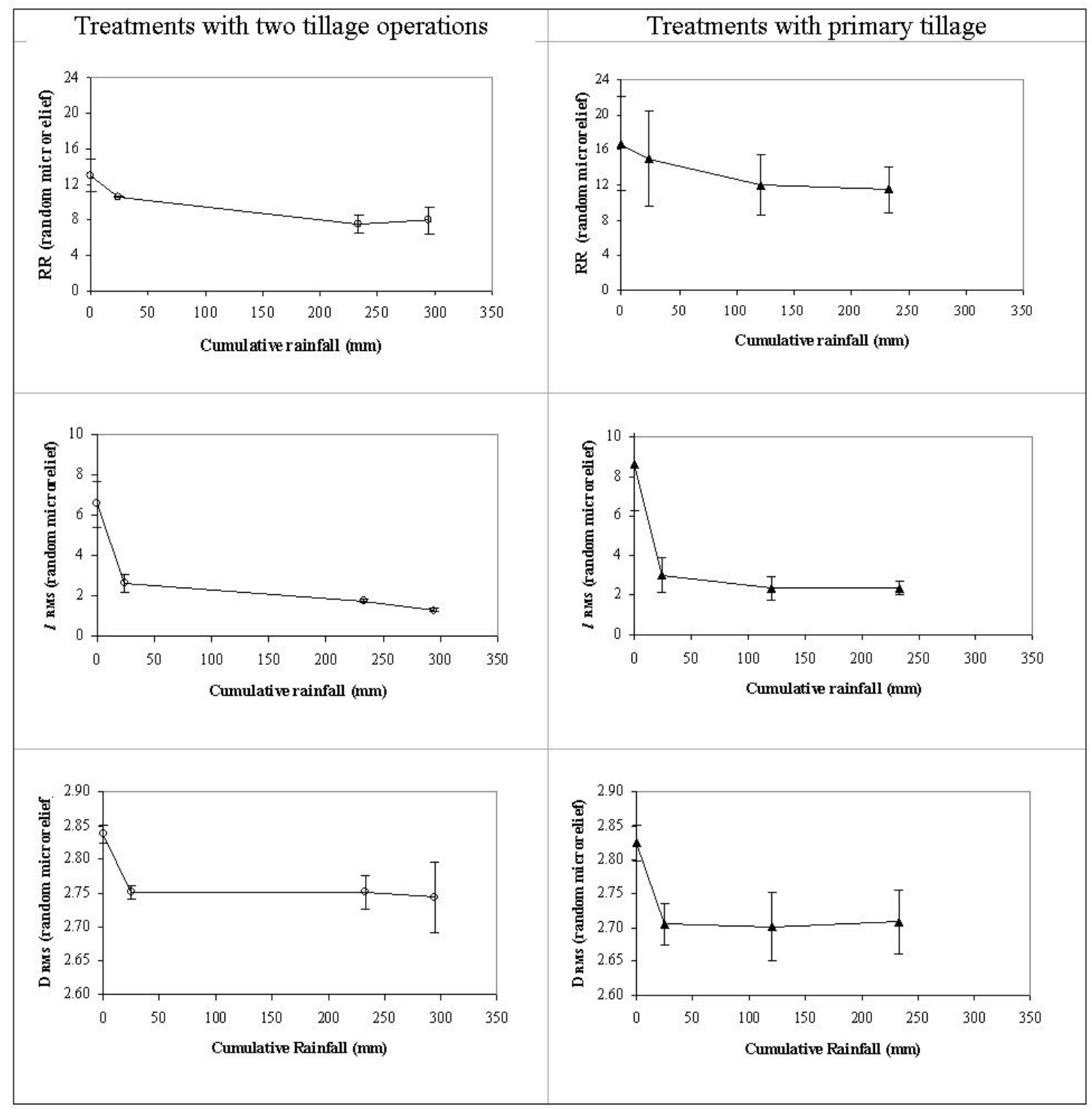

Fig. 4. Random roughness, RR, fractal dimension, $\mathrm{D}$, and crossover length, $l$, as a function of cumulative rainfall for contrasting tillage treatments, primary tillage and primary tillage + levelling.

Another result concerns the variation of the fractal dimension, D, with increasing cumulative rainfall, showing clearly a decrease from its initial value after the first event with $24.4 \mathrm{~mm}$ rain (Fig. 4). Thereafter changes in D values versus cumulative precipitation are not statistically significant. Notice also the relatively high coefficients of variation of $\mathrm{D}$ values within each group of tillage treatments, i.e. primary tillage or two successive tillage operations. Moreover, decay of $\mathrm{D}$ index is very small, when compared with crossover length, $l$, and both in absolute and relative terms. For the primary tillage treatments $\mathrm{D}$ decayed only by $94 \%$ from its initial values with the first $24.4 \mathrm{~mm}$ rainfall and by $95 \%$ with $232.8 \mathrm{~mm}$ cumulative rainfall; similar results were obtained for the group of surfaces with an addi- tional levelling tillage operation. It is widely accepted that soil roughness can either decrease or increase during rainfall, depending on both the surface initial condition and processes occurring on that surface. Surface sealing processes tend to reduce soil roughness, whereas erosion processes tend to increase roughness because of rill formation (Huang, 1998; Darboux et al., 2002). Since these processes occur simultaneously, with one or the other dominating at different spatial locations, the net result may affect the rate of change of surface roughness during rainfall. Eltz and Norton (1997) conducted field experiments using simulated rain under fallow and soybeans. They also found that the decrease in roughness as measured by the $l$ index was very rapid in the first stages, after which it changed very slowly and reported a similar 
Table 3. Roughness statistical $(\mathrm{RR})$ and fractal indices $(l, \mathrm{D})$ for different conditions of natural rain and tillage. Data from surfaces with oriented and random roughness (values followed by the same letter do not differ statistically, $\mathrm{p}=0.01$ ). Cumulative rainfall: $0 \mathrm{~mm}$.

\begin{tabular}{llllll}
\hline & RR & $l_{\text {SMV }}(\mathrm{mm})$ & $l_{\text {RMS }}(\mathrm{mm})$ & $D_{\text {SMV }}$ & $D_{\text {RMS }}$ \\
\hline Oriented roughness & & & & & \\
Primary tillage & $26.18 \mathrm{~A}$ & $9.95 \mathrm{~A}$ & $7.72 \mathrm{~A}$ & $2.70 \mathrm{~A}$ & $2.71 \mathrm{~A}$ \\
Two tillage operations & $15.10 \mathrm{~B}$ & $9.01 \mathrm{~A}$ & $6.83 \mathrm{~A}$ & $2.86 \mathrm{~B}$ & $2.82 \mathrm{~B}$ \\
$\begin{array}{l}\text { Random roughness } \\
\text { Primary tillage }\end{array}$ & $16.70 \mathrm{~A}$ & $11.03 \mathrm{~A}$ & $8.62 \mathrm{~A}$ & $2.85 \mathrm{~A}$ & $2.83 \mathrm{~A}$ \\
Two tillage operations & $13.02 \mathrm{~B}$ & $8.31 \mathrm{~B}$ & $6.55 \mathrm{~B}$ & $2.86 \mathrm{~A}$ & $2.84 \mathrm{~A}$ \\
\hline
\end{tabular}

Table 4. Cumulative rainfall: $232.8 \mathrm{~mm}$.

\begin{tabular}{|c|c|c|c|c|c|}
\hline & $\mathrm{RR}$ & $l_{\mathrm{SMV}}(\mathrm{mm})$ & $l_{\mathrm{RMS}}(\mathrm{mm})$ & $\mathrm{D}_{\mathrm{SMV}}$ & $\mathrm{D}_{\mathrm{RMS}}$ \\
\hline \multicolumn{6}{|l|}{ Oriented roughness } \\
\hline Primary tillage & $19.55 \mathrm{~A}$ & $2.85 \mathrm{~A}$ & $2.11 \mathrm{~A}$ & $2.57 \mathrm{~A}$ & $2.60 \mathrm{~A}$ \\
\hline Two tillage operations & $12.97 \mathrm{~B}$ & $2.76 \mathrm{~A}$ & $1.86 \mathrm{~A}$ & $2.71 \mathrm{~B}$ & $2.69 \mathrm{~B}$ \\
\hline \multicolumn{6}{|l|}{ Random roughness } \\
\hline Primary tillage & $11.48 \mathrm{~A}$ & $3.31 \mathrm{~A}$ & $2.34 \mathrm{~A}$ & $2.71 \mathrm{~A}$ & $2.71 \mathrm{~A}$ \\
\hline Two tillage operations & $7.49 \mathrm{~B}$ & $2.61 \mathrm{~B}$ & $1.77 \mathrm{~B}$ & $2.77 \mathrm{~A}$ & $2.75 \mathrm{~A}$ \\
\hline
\end{tabular}

trend of RR decay as found in our work. D values however decreased before starting to increase. On a laboratory experiment Huang (1998) found that fractal dimension, D, exhibited increasing or decreasing trends after raining depending on slope, thus on the importance of erosive processes. Thus, previous works support the different variation pattern of RR, $l$ and $\mathrm{D}$ indices under rainfall conditions.

Table 3 lists mean values of the statistical index RR and two fractal indices, $l$ and D per surface condition (oriented or random), per tillage type for two contrasting conditions: initial conditions (i.e. just after tillage before rain) and for a cumulative natural rainfall of $232.8 \mathrm{~mm}$. The second stage represents a degraded soil surface. Irrespective of tillage treatment and microrelief condition (oriented or random) RR, $l$ and $\mathrm{D}$ decreased as

As expected, indices describing the vertical component of roughness, RR and $l$ decreased from oriented to random condition. In contrast, mean D increased after removal of agricultural tillage marks. Again soil surfaces with random microrelief condition look smoother and more rugged than those with oriented microrelief.

Treatments with primary tillage exhibited mean RR and $l$ values higher and mean $\mathrm{D}$ values lower than treatments with two successive tillage operations. Surfaces with two successive tillage operations are smoother and more rugged than those with primary tillage, which means that the second tillage operation produces mainly variations at finest scales, resulting in more contrast in point elevation distributions.

In spite of the usefulness of the fractal approach for soil microrelief characterization, differences on the vertical com- ponent of soil surface roughness between one single or two successive tillage operations were better discriminated by RR than by $l$ index $(\mathrm{P}<0.01)$. As a matter of fact, for oriented roughness conditions crossover length, $l$, statistics poorly discriminates between the two kinds of field surfaces in this study. This was irrespective of soil surface evolution stage, i.e. initial state or staged degraded by rainfall.

Furthermore, when the random roughness condition is considered, both RR and $l$ values at the initial state and after $232.8 \mathrm{~mm}$ rainfall are significantly different for these two groups of soil surfaces with contrasting tillage. This means that the sensitivity of $l$ to describe the vertical component of roughness decay is lower than those of RR when the initial and a degraded state are compared. Thus on this type of surfaces, the crossover length index, $l$, behaves only as a very sensitive indicator of roughness decay during the first stages of soil surface evolution and as soil degradation by rainfall progresses RR discriminates better than $l$.

On the other hand in surfaces with oriented microrelief, fractal dimension, $\mathrm{D}$, values allowed discrimination between primary tillage and two successive tillage operations. In opposite, D differences were not statistically significant $(\mathrm{P}<0.01)$ when these two contrasting treatments were compared for the random microrelief condition. This is in accordance with results obtained by Vidal Vázquez et al. (2006) in a comparison of direct drilled and conventional tilled soil surfaces.

Also note that oriented roughness is characteristic of a specific tillage tool and the periodic patterns induced by each tool are relatively easy to quantify by a single geometric 
value. However, spatial patterns of distribution of aggregates and clods conforming random microrelief appeared to be more difficult to quantify.

3.3 Covariance analysis of vertical and horizontal roughness components

The RR indicator, irrespective of cumulative rainfall amount, best assesses differences between tillage treatments, i.e. soil surface evolution stage. The main drawback of the standard statistical index random roughness lies in its no spatial nature. The monofractal approach yields two indices, fractal dimension, $\mathrm{D}$, and crossover length, $l$, and the first one being the less sensitive to microrelief changes due to tillage or induced by cumulative rainfall. These results illustrate the reason why the use of fractal indices in practice remains challenging.

The sensitivity of a given index, however, may increase in cases where a statistically significant dependence with a second auxiliary variable occurs. In a previous work (Vidal Vázquez et al., 2006) a covariance analysis using crossover length, $l$, as a secondary variable improved the sensitivity of $\mathrm{D}$ for describing differences in tillage for random microrelief conditions. Next, the usefulness of covariance analysis between $\mathrm{D}$ and $l$ will be examined.

In the random roughness condition, for five out of six different tillage treatments, crossover length, $l_{\mathrm{RMS}}$, and fractal dimension, $\mathrm{D}_{\mathrm{RMS}}$, values estimated for the five out of six individual tillage treatments were significantly correlated $(\mathrm{P}<0.01)$, the exception being the chisel + levelling tillage treatment (Fig. 5). The following relationships between $\mathrm{D}_{\mathrm{RMS}}$ and $l_{\mathrm{RMS}}$ were obtained by regression analysis:

Disc ploughing $\mathrm{D}=0.019 l+2.61 ; \mathrm{R}^{2}=0.98$

Harrowing $\mathrm{D}=0.018 l+2.66 \mathrm{R}^{2}=0.82$

Chisel ploughing $\mathrm{D}=0.029 l+2.67 \mathrm{R}^{2}=0.78$

Disc ploughing + levelling $\mathrm{D}=0.028 l+2.68 \mathrm{R}^{2}=0.95$

Harrowing + levelling $\mathrm{D}=0.018 l+2.70 \mathrm{R}^{2}=0.83$

Chisel ploughing + levelling no significant relationship between $\mathrm{D}$ and $l$

Note that these significant correlations are an expected result from equations (3) and (7) relating crossover length, $l$, with structural SMV, $\gamma(h)$, and RMS W $(h)$ functions to the Hurst exponent, $\mathrm{H}$.

The above relationships between $l$ and $\mathrm{D}$ were also significant $(\mathrm{P}<0.05)$ for calculations performed by the SMV method. Thus, within each treatment, as the surface roughness increases, the fractal dimension, $\mathrm{D}$, also tends to increase. Different fractal dimension, D, and crossover length, $l$, values were associated with different soil tillage systems. For example in the primary tillage treatments harrowing had a pattern of scaling that was intermediate between disc plow-
Treatments with primary tillage
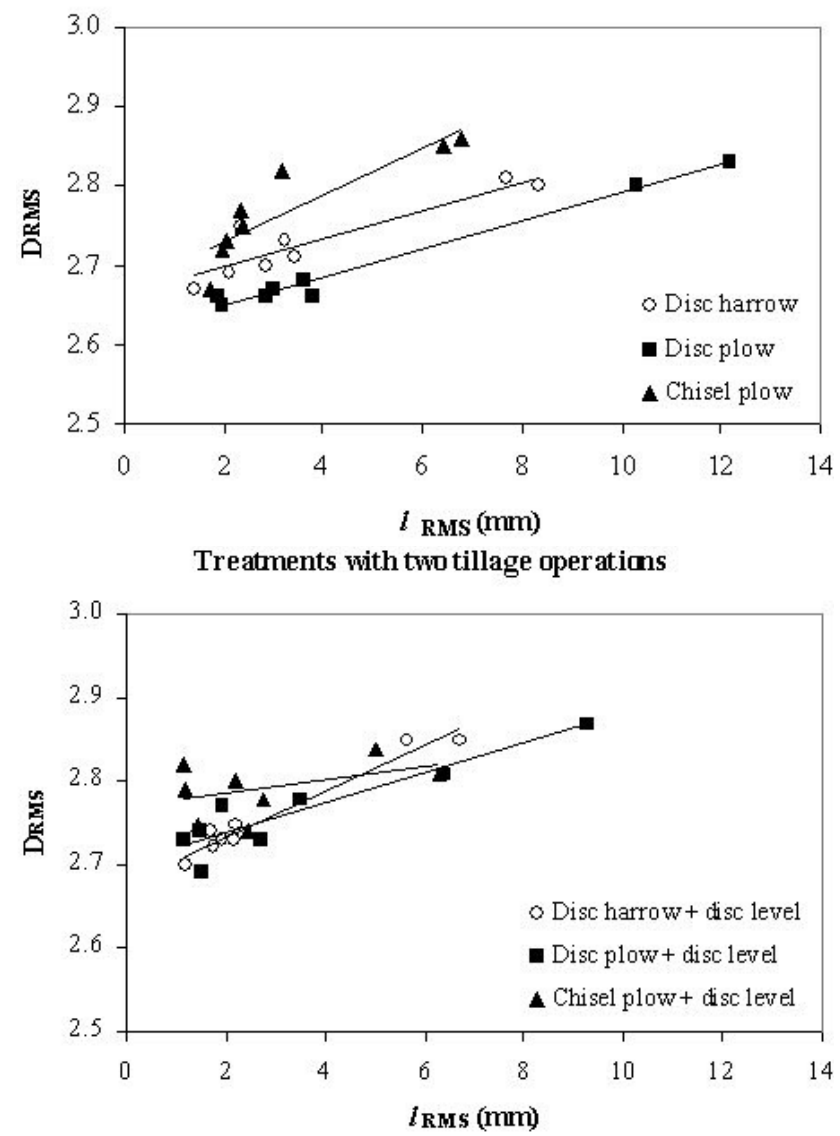

Fig. 5. Relationship between crossover length, $l$, and fractal dimension, $\mathrm{D}$, for five different tillage treatments.

ing and chiseling. This is also in accordance with visual observations of microrelief.

Taken into account the correlation between $l$ and $\mathrm{D}$ an analysis of covariance was performed. Using the crossover length, $l$, as a secondary variable, $\mathrm{D}$ values of the study treatments were significantly different $(\mathrm{P}<0.01)$. Overall, using two fractal indices together, fractal dimension, $\mathrm{D}$, and crossover length, $l$, allows reducing the ambiguity in characterizing soil surface roughness by a single index related to the altitude differences. The estimates of fractal dimension and crossover length provide summary information on the effect of rainfall and tillage on soil surface roughness. Alternatively a combination of RR and D indices could be used for characterizing vertical and horizontal configuration of the soil surface, respectively.

Furthermore, the usefulness of the multifractal approach for characterizing soil surface roughness deserves further research. The recent application of multifractal analysis to data sets with a relatively small number of point data measured on a grid (Roisin, 2007) is encouraging. 


\section{Conclusions}

Soil surfaces with both, oriented and random structural features showed spatial correlation at scales smaller than a few centimeters. Stable estimates of two fractal indices, fractal dimension, $\mathrm{D}$, and crossover length, $l$, were obtained by two different algorithms, semivariogram and root-mean-square.

Changes of initial roughness induced by rainfall were smaller in treatments with an additional levelling operation than in primary tillage treatments. Mean values of random roughness, RR, crossover length, $l$, and fractal dimension, $\mathrm{D}$, measured immediately after tillage rapidly decreased with the first rainfall event. Crossover length, $l$, was the index showing a larger decay during this initial surface degradation stage. However, during successive rainfall events $l$ decreased more slowly. Changes in $\mathrm{D}$ values versus cumulative precipitation were lower, both in absolute and relative terms.

For the studied data set, the statistical index random roughness, RR, allows a better discrimination of the effect of tillage on the vertical component of soil microtopography than the fractal index crossover length, $l$. Use of random roughness, RR, or crossover length, $l$, together with fractal dimension, $\mathrm{D}$, allow a joint description of vertical and horizontal soil roughness variations and provides the best suited characterization of soil surface microrelief. Description of roughness features by a single parameter accounting for the vertical component has proven to be inadequate.

Acknowledgements. This work was made in the frame of research projects PHB 2003-0043-PC, financed by CAPES (Brazil) and MEC (Spain), CGL2005 - 08219 - C02-01 - HID also financed by MEC (Spain) and PGIDIT05RAG10302PR financed by Xunta de Galicia.

Edited by: A. Tarquis

Reviewed by: three referees

\section{References}

Allmaras, R. R., Burwell, R. E., Larson, W. E., and Holt, R. F.: Total porosity and random roughness of the interrow zone as influenced by tillage, USDA Conservation Res. Rep., 7, 22 pp., 1966.

Armstrong, A. C.: On the fractal dimensions of some transient soil properties, J. of Soil Sci., 37, 641-652, 1986.

Bertol, I., Amaral, A., Vidal Vázquez E., Paz González, A., Barbosa, F. T., and Brignoni, L. F.: Relações da rugosidade superficial do solo com o volume de chuvas e com a estabilidade dos agregados em água (In Portuguese), Revista Brasileira de Ciência do Solo, 30 (3), 543-555, 2006.

Bolviken, B., Stokke, P. R., Feder, J., and Jossang, T.: The fractal nature of geochemical landscapes, J. Geochem. Explor., 43, 91109, 1992.

Burrough, P. A.: Book Review of Fractals in Soil Science, in: Developments in Soil Science 27. Elsevier Science, edited by: Pachepsky, Y. A., Crawford, J. W., and Rawls, W. J., Amsterdam, 2000, European Journal of Soil Science, 52, 527-528, 2001.
Carr, A. D. and Benzer, W. B.: On the practice of estimating fractal dimension, Math. Geol., 23, 945-958, 1991.

Currence, H. D. and Lovely, W. G.: The analysis of soil surface roughness, Trans. ASAE, 13, 710-714, 1970.

Darboux, F., Gascuel-Odoux, C., and Davy, P.: Effects of surface water storage by soil roughness on overland-flow generation, Earth Surface Processes and Landforms, 27(3), 223-233, 2002.

Darboux, F. and Huang, C. H.: Does soil surface roughness increase or decrease water and particle transfer?, Soil Sci. Soc. Am. J., 69, 748-756, 2005.

Davies, S. and Hall, P.: Fractal analysis of surface roughness by using spatial data, Journal of the Royal Statistical Society (Series B), Statistical Methodology, 61(1), 3-37, 1999.

Eltz, F. L. F. and Norton, L. D.: Surface roughness changes as affected by rainfall erosivity, tillage, and canopy cover, Soil Sci. Soc. Am. J., 61, 1746-1755, 1997.

EMBRAPA: Sistema Brasileiro de Classificaçao de Solos (In portuguese), Embrapa Solos, Rio de Janeiro, 1999.

Favis-Mortlock, D. T., Boardman, J., Parsons, A. J., and Lascelles, B.: Emergence and erosion: a model for rill erosion and development, Hydrol. Processes, 14, 2173-2205, 2000.

Gallant, J. C., Moore, I. D., Hutchinson, M. F., and Gessler, P.: Estimating fractal dimension of profiles: a comparison of methods, Mathematical Geology, 26, 455-481, 1994.

Hairsine, P. B., Moran, C. J., and Rose, C. W.: Recent developments regarding the influence of soil surface characteristics on overland flow and erosion, Aus. J. Soil. Res., 30, 249-264, 1992.

Hansen, B., Schönning, P., and Sibbesen, E.: Roughness indices for estimation of depression storage capacity of tilled soil surfaces, Soil and Tillage Research, 52, 103-111, 1999.

Huang, C. and Bradford J. M.: Depressional storage for MarkovGaussian surfaces, Water Resour. Res., 26, 2235-2242, 1990.

Huang, C. and Bradford J. M.: Applications of a laser scanner to quantify soil microtopography, Soil Sci. Soc. Am. J., 56, 14-21, 1992.

Huang, C.: Quantification of soil microtopography and surface roughness, in: Fractals in Soil Science, edited by: Baveye, P., Parlange, J. Y., and Stewart, B. A., 377 pp, 1998.

Jetten, V., de Roo, A., and Favis-Mortlock, D.: Evaluation of fieldscale and catchment-scale soil erosion models, Catena, 37 (3-4), 521-541, 1999.

Kamphorst, E. C., Jetten, V., Guerif, J., Pitkanen, J., Iversen, B. V., Douglas, J. T., and Paz, A.: How to predict maximum water storage in depressions from soil roughness measurements, Soil Sci. Soc. Am. J., 64, 1749-1758, 2000.

Keirsbulck, L., Labraga, L., Mazouz, A., and Tournier, C.: Influence of surface roughness on anisotropy in a turbulent boundary layer flow, Experiments in Fluids, 33 (3), 497-499, 2002.

Klinger, D., Lusakowska, E., and Zymierska, D.: Nano-structure formed by nanosecond laser annealing on amorphous Si surface, Materials Science in Semiconductor Processing, 9(1-3), 323326, 2006.

Linden D. R. and van Doren, D. M.: Parameters for characterizating tillage induced soil surface roughness, Soil Sci. Soc. Am. J., 50, 1560-1565, 1986.

Malinverno, A.: A single method to estimate the fractal dimension of self-affine series, Geophys. Res. Lett., 17 (11), 1953, 1990.

Mandelbrot, B. B.: The fractal geometry of nature, Freeman, San Francisco, 1983. 
Merril, S. D., Huang, C., Zobeck, T. M., and Tanaka, D. L.: Use of the chain set for scale-sensitive and erosion-relevant measurements of soil surface roughness, in: Sustaining the global farm, edited by: Stott, D. E., Mothar R. H., and Steihardt, D. C., 594600, 2001.

Miranda, J. G. V.: Análisis fractal del microrrelieve del suelo (In Spanish), Ph. D. Dissertation, University of Coruña, Spain, 313 pp, 2000.

Miranda, J. G. V. and Paz González, A.: Fractal models for the description of soil surface roughness, in: Man and Soil at the Third Millenium, edited by: Rubio, J. L., Morgan, R. P. C., Asins, S., and Andreu, V., Geoforma Ediciones, Logroño (Spain), 20992112, 2002.

Moreira, J. G. and Da Silva, K. L.: On the fractal dimension of profiles, J. Phys. A., 27, 8079-8089, 1994.

Pachepsky, J. and Ritchie, J. C.: Seasonal changes in fractal landscape surface roughness estimated from airborne laser altimetry data, Journal of Remote Sensing, 19, 2509-2516, 1998.

Power, W. L. and Tullis, T. E.: Euclidean and fractal models for the description of rock surface roughness, J. Geophys. Res., 96, 415-424, 1991.

Roisin, C. J. C.: A multifractal approach for assessing the structural state of tilled soils. Soil Sci. Soc. Am. J., 71, 15-25, 2007.
Saitou, M., Hokama, M., and Oshikawa, W.: Scaling behavior of polished (1 110$)$ single-crystal nickel surfaces, Applied Surface Science, 185(1-2), 79-83, 2001.

Soil Survey Staff Division: Soil survey manual, USDA Handb. 18. U.S. Gov. Print. Office. Washington DC, 1993.

Takken, I., Jetten, V., Govers, G., Nachtergaelle, J., and Steegen, A.: The effect of tillage-induced roughness on runoff erosion patterns, Geomorphology, 37 (1-2), 1-14, 2001.

Vidal Vázquez, E.: Influencia de la precipitación y el laboreo en la rugosidad del suelo y la retención de agua en microdepresiones (In Spanish), Ph. D. Dissertation, University of Coruña, Spain, 430 pp, 2002.

Vidal Vázquez, E., Paz González, A., and Vivas Miranda, J.G.: Characterizing isotropy and heterogeneity of soil surface microtopography using fractal models, Ecological Modelling, 182, 337-353, 2005.

Vidal Vázquez, E., Miranda, J. G. V., Alves, M. C., and Paz González, A.: Effect of tillage on fractal indices describing soil surface microrelief of a Brazilian Alfisol, Geoderma, 134 (3-4), 428-439, 2006.

Wagner, L. E. and Yiming, Yu: Digitization of profile meter photographs, Trans. Am. Soc. Agric. Eng., 34 (2), 412-416, 1991. 